\title{
X-Ray crystallography investigation of bimetallic Iron-nucleotide ternary coordination complexes
}

\author{
A. K. Pal, M. Nethaji \\ Department of Inorganic and Physical Chemistry, Indian Institute of Science, Bangalore India \\ mnetaji@iisc.ac.in
}

Nucleotides are the building blocks of DNA and RNA. Metal ion play a key role for their functional activities and stability. ${ }^{[1]}$ As nucleotide contains multiple functional groups, such as nucleobases, phosphate group and hydroxyl in the sugar moiety, it is therefore necessary to know the affinities of different coordination donor of nucleotide towards a particular metal ion. In this regard, X-ray investigation have made an important contribution by providing accurate information on the geometry of metal binding to the nucleotides. Molecular structure of these metal-nucleotide complex help to understand specific interaction at a certain condition which set the stage for biological and material applications. ${ }^{[2]}$ In this present work we are specifically synthesized the monomeric structure with phosphate only metal binding where we used ferric ion as metal centre. This is the first example of Iron (III)-Nucleotide ternary complex where we used tripodal tetradentate ligand as an auxiliary ligand. Single crystal X-ray diffraction showed that crystal of $\left[\mathrm{Fe}_{2} \mathrm{O}(\mathrm{TPA})_{2}(\mathrm{AMP})\right]\left(\mathrm{ClO}_{4}\right)_{2}[\mathrm{TPA}=$ Tris pyridyl methyl amine; $\mathrm{AMP}=$ Adenosine 5'-monophosphate $]$ and $\left[\mathrm{Fe}_{2} \mathrm{O}(\mathrm{TPA})_{2}(\mathrm{CMP})\right]\left(\mathrm{ClO}_{4}\right)_{2}$ $[\mathrm{CMP}=$ Cytosine 5 '-monophosphate] were crystallized in the triclinic crystal system (space group type $P 1$ ). In these two structures we observed different packing arrangements of the nucleobase moiety with respect to the metal free counterpart. Here we observed adenine-adenine (Ade-Ade) and cytidine-cytidine (Cyt-Cyt) hydrogen bond formation from two different molecules in the unit cell. Because of the non-coplanar "nature" of auxiliary ligand, we didn't find $\pi-\pi$ stacking interaction between TPA ligand and nucleobase, but it is believed that TPA ligand is providing hydrophobic atmosphere which is important for forming H-bonding "interaction" between nucleobases. In case of $\left[\mathrm{Fe}_{2} \mathrm{O}(\mathrm{TPA})_{2}(\mathrm{GMP})\right]\left(\mathrm{ClO}_{4}\right)_{2}\left[\mathrm{GMP}=\mathrm{Guanosine} 5^{\prime}\right.$ '-monophosphate $]$ and $\left[\mathrm{Fe}_{2} \mathrm{O}(\mathrm{TPA})_{2}(\mathrm{IMP})\right]\left(\mathrm{ClO}_{4}\right)_{2}$ [IMP=Inosine 5'-monophosphate] belong to the monoclinic system, space group $P 2_{1}$ and $C 2$ where we found that guanine moiety is making $\pi-\pi$ stacking interaction with another guanine moiety and hypoxanthine is hydrogen bonded with another hypoxanthine moiety through bifurcating water molecule. As all the nucleotides are chiral in nature, we records CD spectra of free nucleotide and Ironnucleotide complexes in liquid state to understand the chirality of nucleotide-metal complexes and supramolecular assemblies.

a

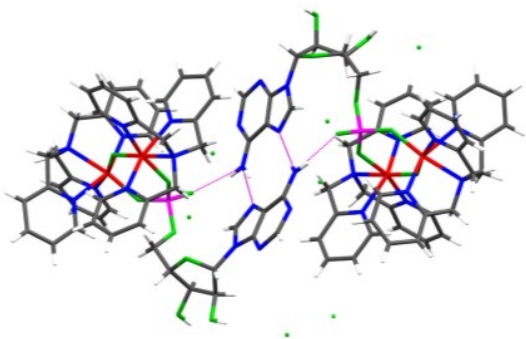

$\mathrm{b}$

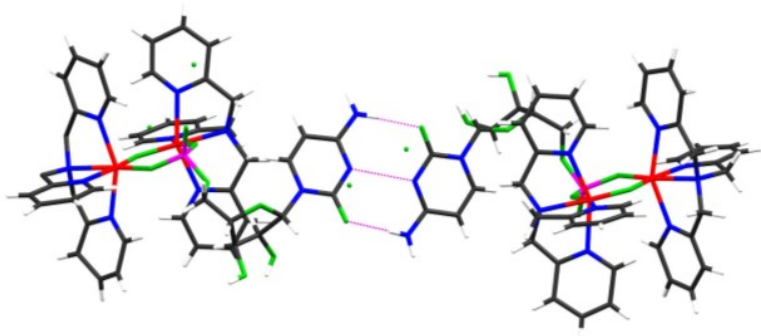

c

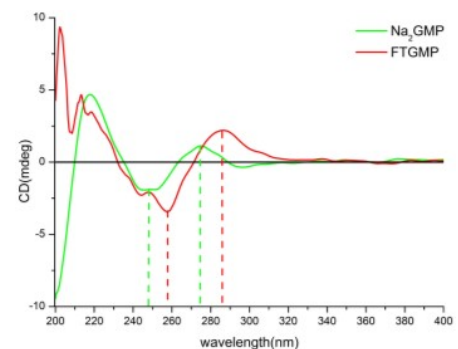

Figure 1. (a)Crystal structure of $\left[\mathrm{Fe}_{2} \mathrm{O}(\mathrm{TPA})_{2}(\mathrm{AMP})\right]\left(\mathrm{ClO}_{4}\right)_{2} \cdot 6 \mathrm{H}_{2} \mathrm{O}$ (b) Crystal structure of $\left[\mathrm{Fe}_{2} \mathrm{O}(\mathrm{TPA})_{2}(\mathrm{CMP})\right]\left(\mathrm{ClO}_{4}\right)_{2} \cdot 8 \mathrm{H}_{2} \mathrm{O}$ (c)Comparison of CD spectra between $\mathrm{Na}_{2} \mathrm{GMP}$ and $\left[\mathrm{Fe}_{2} \mathrm{O}(\mathrm{TPA})_{2}(\mathrm{GMP})\right]\left(\mathrm{ClO}_{4}\right)_{2}$ in water.

[1] G. L. Eichhorn and Y. A. Shin. (1968). J. Am. Chem. Soc. 90, 7323.

[2] Zhou P., Shi R., Yao J.F., Sheng C.F., Li H. (2015). Coordination Chemistry Reviews. $292,107$.

Keywords: Metal-nucleotide interactions; ternary complex; single crystal structure 